\title{
APRENDIZAGEM INTERDISCIPLINAR: CONSTRUÇÃO DE UM ROBÔ ANIMATRÔNICO CAPAZ DE CONTAR HISTÓRIAS PARA CRIANÇAS
}

Marcos E. Nepomuceno-marcos.nepomuceno@unifeb.edu.br

Centro Universitário da Fundação Educacional de Barretos - UNIFEB

Av. Prof. Roberto Frade Monte, 389 - Aeroporto

Barretos - SP, 14783-226

Caren E. Studer - carencaetano@gmail.com

Centro Universitário da Fundação Educacional de Barretos - UNIFEB

Av. Prof. Roberto Frade Monte, 389 - Aeroporto

Barretos - SP, 14783-226

Silvia Bortolo - silvia.bortolo@unifeb.edu.br

Centro Universitário da Fundação Educacional de Barretos - UNIFEB

Av. Prof. Roberto Frade Monte, 389 - Aeroporto

Barretos - SP, 14783-226

Gleiciene C.de Gois-gleiciene.gois@sou.unifeb.br

Centro Universitário da Fundação Educacional de Barretos - UNIFEB

Av. Prof. Roberto Frade Monte, 389 - Aeroporto

Barretos - SP, 14783-226

Rodrigo D. L. Alfena-rodrigo.alfena@sou.unifeb.edu.br

Centro Universitário da Fundação Educacional de Barretos - UNIFEB

Av. Prof. Roberto Frade Monte, 389 - Aeroporto

Barretos - SP, 14783-226

Resumo: $O$ relato deste artigo se refere a uma experiência interdisciplinar dos cursos de Engenharia Elétrica e Pedagogia. Refere-se à construção de um robô animatrônico com feições humanas e aparência de uma velha bruxa que se levanta de um baú de madeira e interage com a plateia contando histórias infantis criadas pelos alunos do curso de Pedagogia. O projeto foi desenvolvido por professores e alunos dos cursos acima citados e coordenado pelo Centro de Inovação Tecnológica (CIT) do UNIFEB. A interação técnica e profissional de todos os envolvidos foi fundamental para o êxito da proposta inicial.

Palavras-chave: Robôs animatrônicos. Ensino interdisciplinar. Engenharia Elétrica. Contação de história infantil. 


\section{INTRODUÇÃO}

O objetivo deste trabalho se refere a um relato interdisciplinar da construção de um equipamento didático - um robô animatrônico - envolvendo o Centro de Inovação Tecnológica (CIT), o Núcleo de Apoio Pedagógico (NAPe) e os Cursos de Pedagogia e Engenharia Elétrica do Centro Universitário da Fundação Educacional de Barretos (UNIFEB).

Este equipamento consiste em um baú de madeira $(0,95 \mathrm{~m}$ de largura, $0,93 \mathrm{~m}$ de altura e 0,65m de profundidade, Figura 1.0), no qual se instalou um robô animatrônico no formato de uma bruxa, personagem contadora de histórias infantis. Trata-se de um equipamento móvel que pode ser levado a diferentes contextos da educação infantil, como ferramenta pedagógica da área de contação de histórias envolvendo os alunos dos cursos de Pedagogia e Engenharia Elétrica.

Figura 1.0 - Baú de Histórias Animatrônico

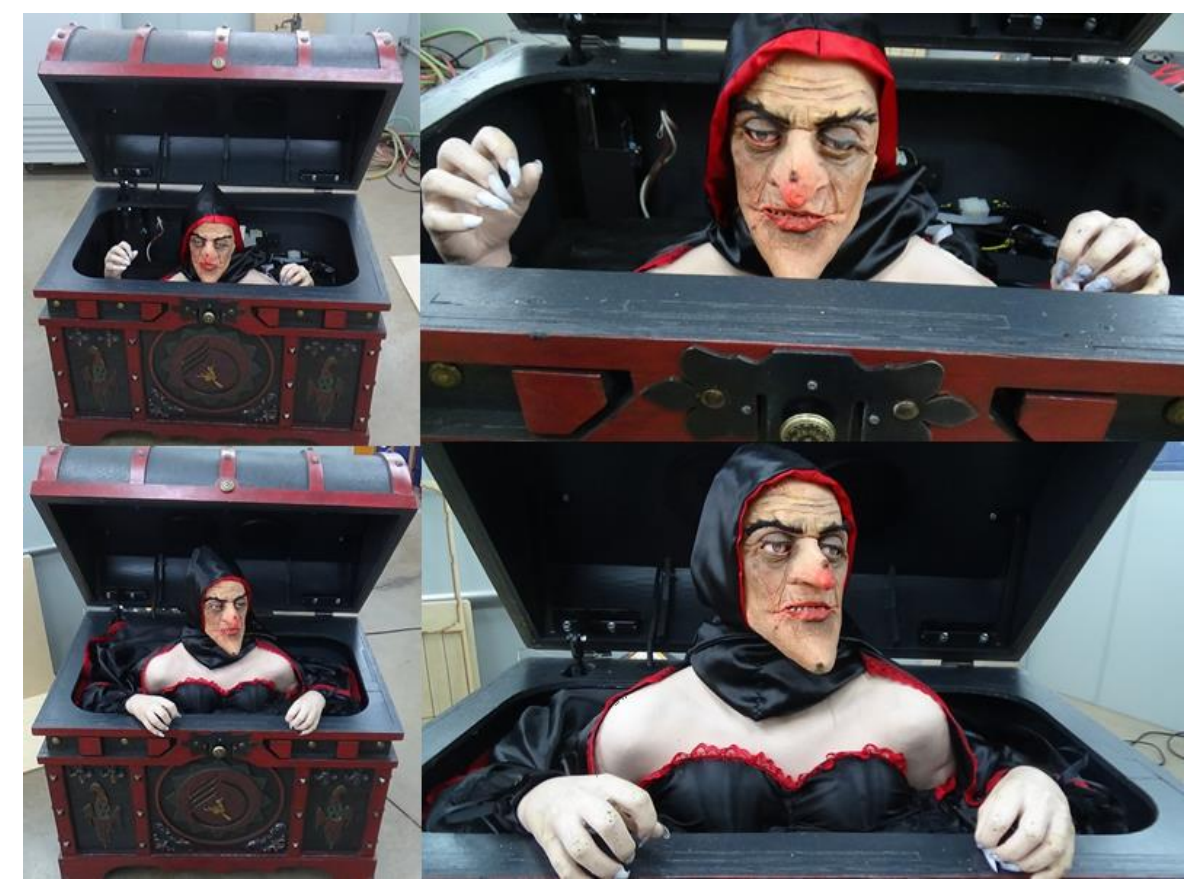

Fonte: Própria

A ferramenta possibilita a reprodução de histórias previamente selecionadas e gravadas, as quais são interpretadas por uma personagem com movimentos mecânicos sincronizados com o conteúdo e o áudio da história.

O contexto pedagógico deste relato se refere ao cenário de inovação tanto da formação pedagógica oferecida aos alunos do Curso de Pedagogia como dos ambientes profissionais dos futuros engenheiros eletricistas, atualmente situados em patamares disruptivos, tais quais os indicados pela obra organizada por Fabio Reis (2018). Por outro lado, o desenvolvimento deste equipamento em específico, evidencia a modelagem acadêmica Hands On proposta pela IES, na qual se procura adicionar competências práticas aos conteúdos teóricos de cursos tradicionais como Pedagogia e Engenharia Elétrica (MORAN et al. 2012). O desenvolvimento deste equipamento se circunscreve ainda em uma prática interdisciplinar entre dois cursos aparente com conteúdos distantes entre si, como os da Engenharia Elétrica e os da Pedagogia (HORN e STAKER, 2014; FAZENDA, 2017). As propostas de flexibilização das pedagogias e das metodologias de aulas tradicionais em andamento por 
diversos autores mundo afora, tais como Bergmann e Sams (2016) ou então Leal (et al. 2017) se constituem em exemplos inspiradores de metodologias ativas dentro das práticas oferecidas pelo UNIFEB, sendo este relato uma das inúmeras experiências em metodologias ativas em andamento na instituição.

Para além dos aspectos metodológicos, há de se considerar ainda a área acadêmica relacionada à aprendizagem da literatura infantil. Essa disciplina, significativa no desenvolvimento de futuros professores da área, oferece um espaço para o ato de contar e ouvir histórias, criar e elaborar textos infantis transformando o aluno em um autor e contador de histórias. Nesse processo, o estudante passa a compreender a importância da construção do conhecimento e do desenvolvimento social, emocional e cognitivo da criança, além do despertar para a comunicação linguística "que, nos primeiros anos é fundamental para que se processe uma relação ativa entre falante e língua" (CADERMATORI,2008). Além do mais, o trabalho com as narrativas infantis proporciona o desenvolvimento da imaginação, da criatividade e da capacidade de contar histórias ouvidas, inventadas ou recriadas na ótica da criança (LAJOLO E ZILBERMAN, 2010). As histórias contadas, a princípio, de geração a geração, de forma oral, com o passar do tempo, foram impressas e divulgadas nos livros e hoje, por uma diversidade de meios eletrônicos, virtuais etc.

A criação do baú, ferramenta para contar histórias, constitui uma forma diferenciada de interação, já que a personagem da bruxa entra em conversa com a criança rompendo a passividade de um filme, vídeo ou áudio, provocando diferentes emoções.

Para a formação dos alunos da Pedagogia, a criação desta ferramenta representa mais uma forma de promover a inclusão de novos horizontes tecnológicos na seara do dia a dia pedagógico que pode ocorrer nos mais diversos espaços além-escola, em que se podem incluir esta caixa de histórias, tais como hospitais, casas de repouso, bibliotecas, livrarias entre tantas outras possibilidades, como bem indicado por Marsiglia (2011).

Quanto à elaboração dos textos narrados pela bruxa, observa-se que os alunos, ao escreverem as narrativas infantis, procuraram aplicar tanto a organização textual como os elementos de coesão e coerência aprendidos, além de uma estrutura dialógica que sensibilizasse as crianças. Percebe-se o cuidado com os elementos orais, com as entonações e as interferências comunicativas os quais valorizam a criação do baú, colaborando também para o processo na elaboração do roteiro, das possíveis interpretações, além de uma autoavaliação sobre a lógica de criação textual. Portanto, entende-se que a bruxa, em seu baú, constitui uma ferramenta de formação pedagógica e de elaboração de textos e narrativas.

Pensando nos alunos da Engenharia Elétrica, a interação propiciada pela construção da ferramenta faz parte dos objetivos da Modelagem Acadêmica atualmente em vigor na área das Exatas, como bem indicado por Oliveira (2019) no que se refere às competências e habilidades sugeridas pelas DCN's novas das Engenharias que passaram a fazer parte do curso. O Perfil de Egresso proposto pelo Curso de Engenharia Elétrica se constitui como exemplo e ponto de ligação dos conteúdos propostos e das vivências práticas e experimentais deste projeto.

\section{OBJETIVO}

Como objetivo geral, o desenvolvimento deste equipamento consiste em proporcionar a interação da arte de escrever e contar histórias com a tecnologia necessária para a sua reprodução por meio de um robô animatrônico. Como objetivos específicos, propõe-se o desenvolvimento das habilidades e competências referentes a cada fase do projeto, desde a 
escrita das histórias, a produção dos áudios de voz, o musical e efeitos sonoros, além da interação que se fez necessária entre duas áreas ou universos anteriormente distantes entre si.

\section{METODOLOGIA}

A animatrônica é uma área da engenharia que trabalha com projeto e desenvolvimento de dispositivos robóticos (do inglês animatronics), projetados para reproduzir algum ser vivo. Estes mecanismos robotizados possuem características estéticas, de movimento e de comportamento que reproduzem com fidelidade as particularidades que seriam encontradas no ser vivo que o dispositivo se propõe a imitar. Os animatrônicos são amplamente utilizados em filmes, efeitos especiais, parques de diversões dentre outras aplicações. Na Figura 2.0, pode-se ver um exemplo de animatrônico desenvolvido nos estúdios de Hollywood.

Figura 2 - Animatrônico dos estúdios de Holliwwod

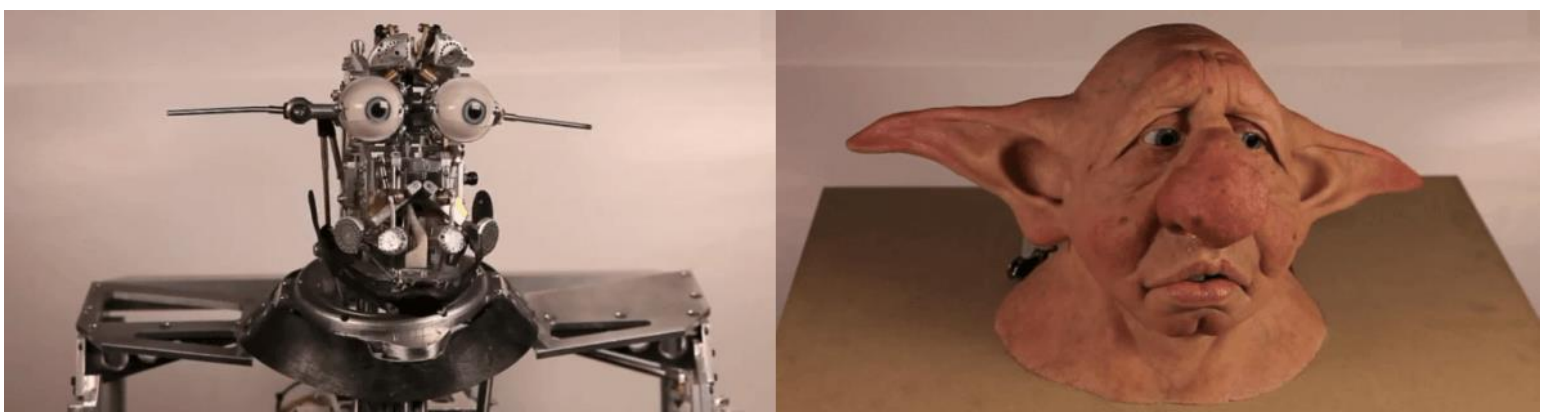

Fonte: https://br.pinterest.com/pin/201043570850358868/_- Acesso em abril de2020

Do ponto de vista da engenharia, a animatrônica dá aos desenvolvedores a possibilidade de projetar o robô em um domínio que une o trabalho técnico ao artístico. A geração de movimento para robôs pode ser expressa em dois extremos distintos. De um lado, têm-se os robôs industriais que são controlados por abordagens estritamente funcionais, como cinemática inversa e prevenção de autolesão. Estes sistemas de geração de movimento que controlam robôs interativos resultam em movimento rígido, antinatural e frequentemente lento ou desajeitado.

Do outro lado, os robôs animatrônicos são roteirizados para processar uma variedade de entradas, incluindo comandos diretos do motor ou mesmo uma ferramenta de animação 3D de forma a propiciar movimentos realísticos. A Hanson Robotics é um dos principais líderes desse setor. Os robôs da Hanson Robotics são surpreendentes no realismo e, por meio de uma máscara flexível, não deixam transparecer o número de atuadores que eles têm embaixo dessa pele. Suas pesquisas em animatrônica criaram robôs que podem ler expressões faciais de um ator como, por exemplo, os robôs Einstein e Jules (HANSON ROBOTICS, 2009).

O primeiro passo deste projeto foi decidir sobre o número de graus de liberdade para imitar todos os movimentos faciais (CRAIG, 2004). Embora o robô Jules use um grande número de atuadores para realizar emoções humanas, os movimentos básicos são os olhos, as pálpebras, as sobrancelhas, a boca e o pescoço.

Esses movimentos podem fluir diretamente para graus discretos de liberdade. A inclinação dos olhos é controlada por dois atuadores, respectivamente, um para cada olho, uma vez que os olhos humanos sempre se movem de forma consonante, a utilização de dois atuadores oferece a possibilidade de o robô olhar para a ponta do nariz.

As pálpebras, pelo mesmo motivo, também são controladas por dois atuadores, pois, na maioria dos casos, as pálpebras são consonantes em seu movimento, com exceção durante o 
piscar que pode ser de apenas um olho. As sobrancelhas foram acopladas a um único atuador, o que impossibilita a elevação de uma sobrancelha separadamente, mas aceitável para evitar a complexidade geral do robô.

A boca foi acoplada a um atuador que faz os movimentos de abrir e fechar, já os lábios inferior e superior são acoplados a dois atuadores distintos o que possibilita movimentos separados para os mesmos. Por fim, o pescoço é controlado por dois atuadores, o giro e a inclinação do pescoço. No total, o sistema foi projetado para ter dez graus de liberdade, dois nos olhos, dois nas pálpebras, um na sobrancelha, dois nos lábios, um na boca e dois no pescoço.

Os atuadores estão todos montados no interior da cabeça do robô, com exceção do atuador de giro do pescoço, que está montado na base de fixação da cabeça. Na Figura 2.1, é possível visualizar a montagem dos atuadores.

Figura 2.1 - Atuadores mecânicos da cabeça do robô.

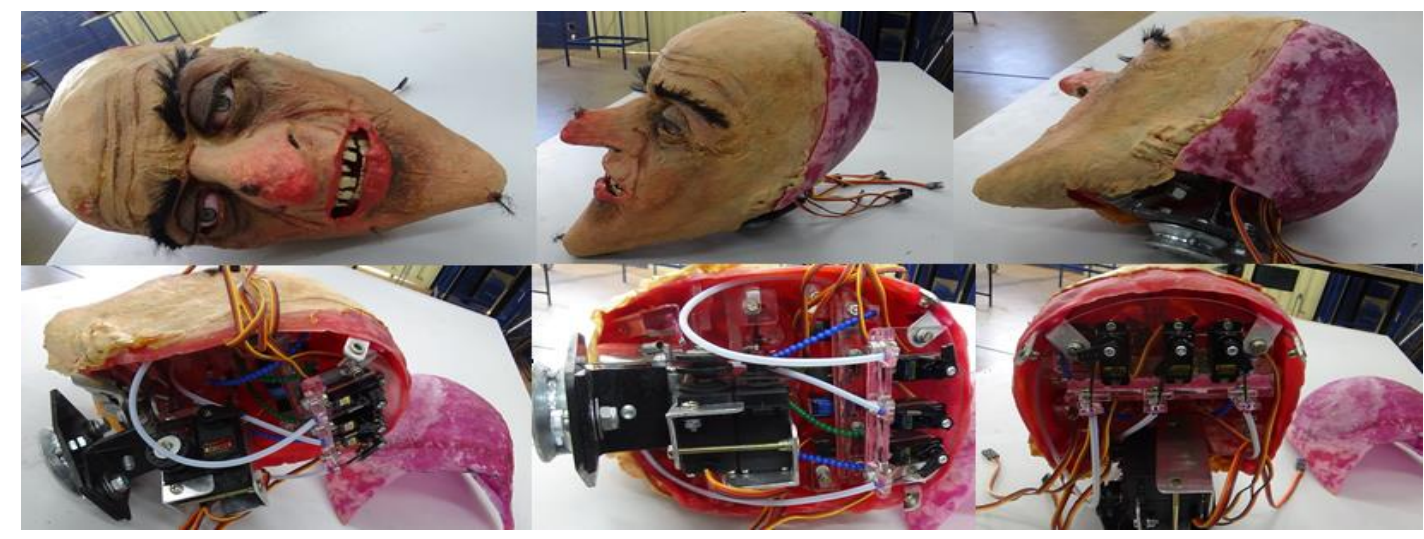

Fonte: Própria

O atuador ou servo motor, como é denominado, é construído por um motor DC, uma caixa de engrenagens, um potenciômetro acoplado ao eixo da haste de atuação e um circuito de controle com Ponte $\mathrm{H}$ montado dentro de uma carenagem. O motor é acoplado por engrenagens na haste de controle (atuador). À medida que o motor gira, a resistência do potenciômetro muda, de modo que o circuito de controle pode controlar com precisão quanto movimento existe e em qual direção. Na Figura 2.2, é mostrado o mecanismo de um servo motor.

Figura 2.2 - Mecanismo do servo motor
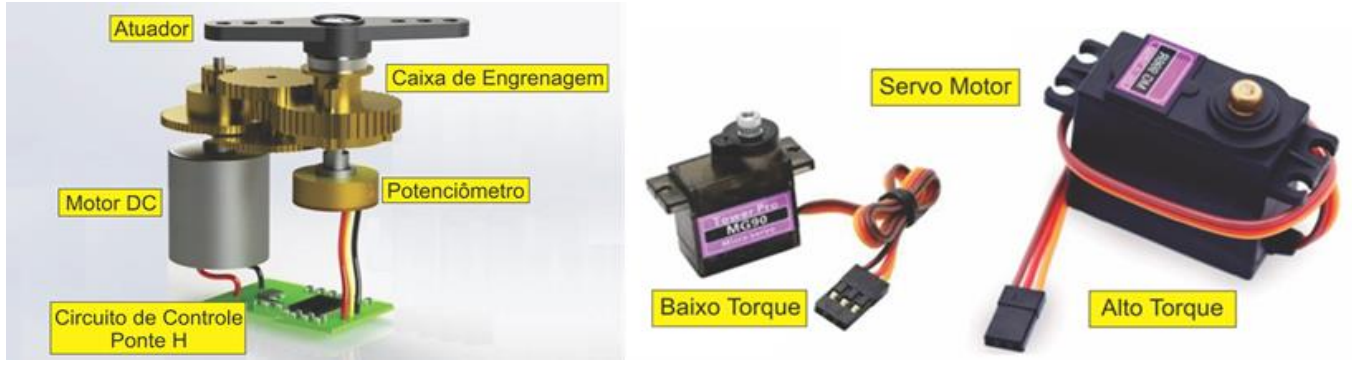

Fonte: Própria 
(C) COBENGE

"Os desafios para formar hoje o engenheiro do amanhã"
$\mathrm{Ol} \mathrm{a} \mathrm{O3}$ de dezembro Evento On-line

Quando o eixo do potenciômetro, que fica acoplado à haste do atuador, estiver na posição desejada, o circuito de controle faz com que a energia elétrica fornecida ao motor seja interrompida; caso contrário, o motor é girado na direção apropriada. A posição desejada é enviada através de um sinal de pulsos elétrico denominado PWM (Pulse width modulation Modulação por largura de pulso) (RAJAN \& SEYEZHAI, 2013). Este sinal consiste em uma portadora de $50 \mathrm{~Hz}$ com largura de pulso modulada e a duração deste pulso determina o posicionamento do atuador e o sentido de giro do motor. Por exemplo, um sinal com largura de $1,5 \mathrm{~ms}$ fará o motor girar para a posição $90^{\circ}$. Quando for menor que $1,5 \mathrm{~ms}$, este move-se no sentido horário em direção à posição $0^{\circ} \mathrm{e}$, quando for maior que $1,5 \mathrm{~ms}$, moverá o motor no sentido anti-horário em direção à posição $180^{\circ}$ como pode ser visto na Figura 2.3.

Figura 2.3 - Posicionamento do atuador em relação ao sinal de PWM
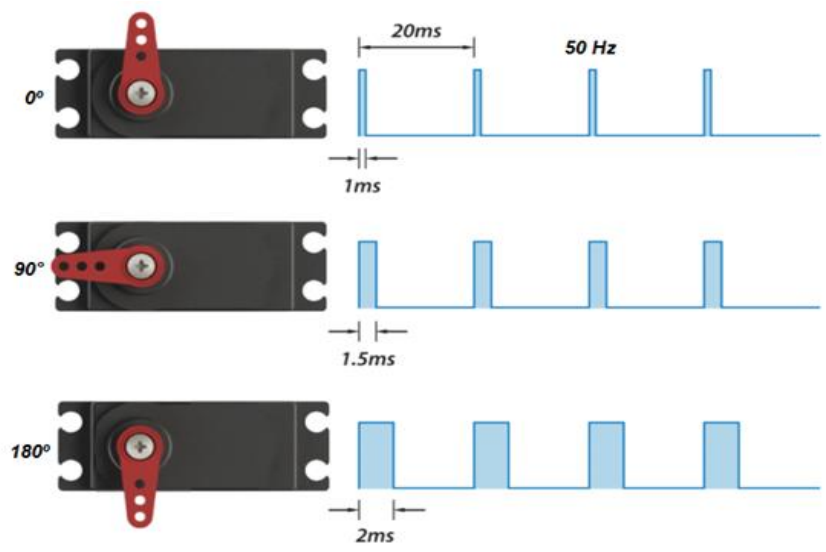

Fonte: Própria

Foram aplicados também dois atuadores de cama hospitalar de $24 \mathrm{~V}_{\mathrm{DC}}$ para efetuarem a abertura da tampa do baú e a movimentação da plataforma de elevação do busto do robô animatrônico para fora da caixa do baú. Os dois são idênticos e mostrados na Figura 2.4.

Figura 2.4 - Atuador $24 \mathrm{~V}_{\text {DC }}$ para cama hospitalar.
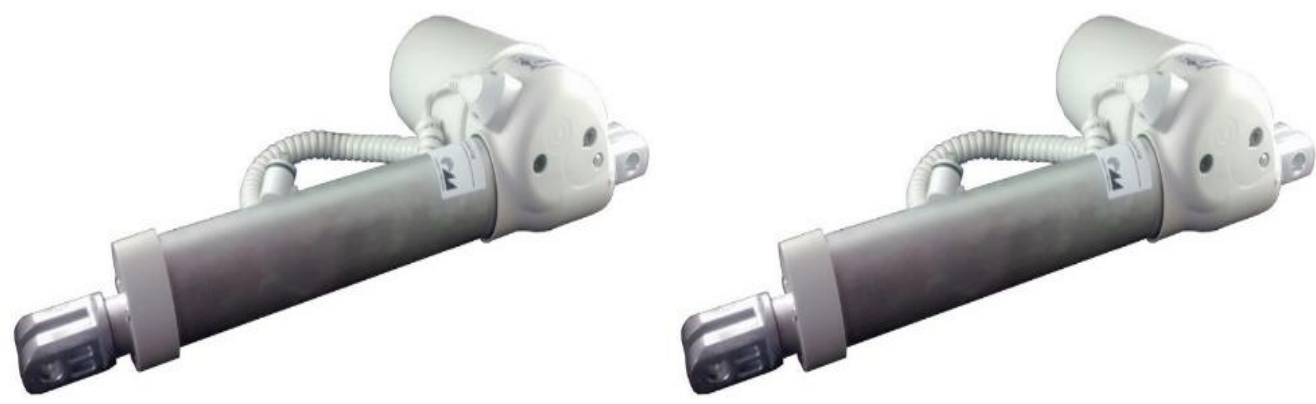

Fonte: https://http2.mlstatic.com/1pc-atuador-cama-hospitalarcurso-100mm-dewert-d51998-D_NQ_NP_662339-

MLB31081894854_062019-F.jpg - Acesso em: 09 abr. 2020.

Neste projeto, também foram incluídos alguns dispositivos para efeitos de cenas, são eles: uma fita de Leds RGB de alta potência posicionada na parte superior da tampa do baú e outra no fundo de forma a iluminar a parte interna e externa do baú com controles individuais, um 
gerador de fumaça densa para simular névoa e um sistema de som autônomo formado por três amplificadores de potência ligados dois alto falantes de duas vias de 6"/15Watts RMS (Root Mean Square - Valor Médio Quadrático) montados na tampa do baú, Figura 2.5 e um alto falante subwoofer de 8"/50Watts RMS montado no fundo do baú.

Figura 2.5 - Alto falante 6"/15Watts RMS de duas vias.

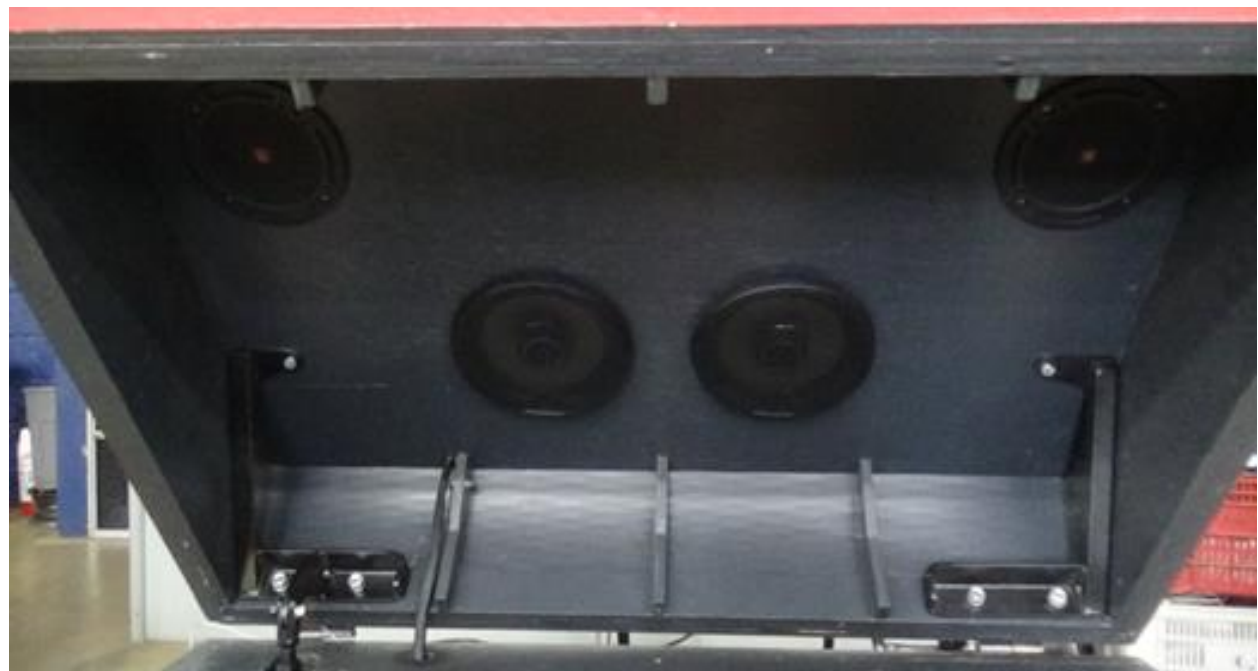

Fonte: Própria

O processamento do sistema foi baseado em uma topologia com aplicação do micro controlador da família Intel 8051 (GIMENEZ, 2010). O hardware e firmware de controle foram desenvolvidos especificamente para esta aplicação, conforme Figura 2.6.

Figura 2.6 - Placa eletrônica de controle do robô.

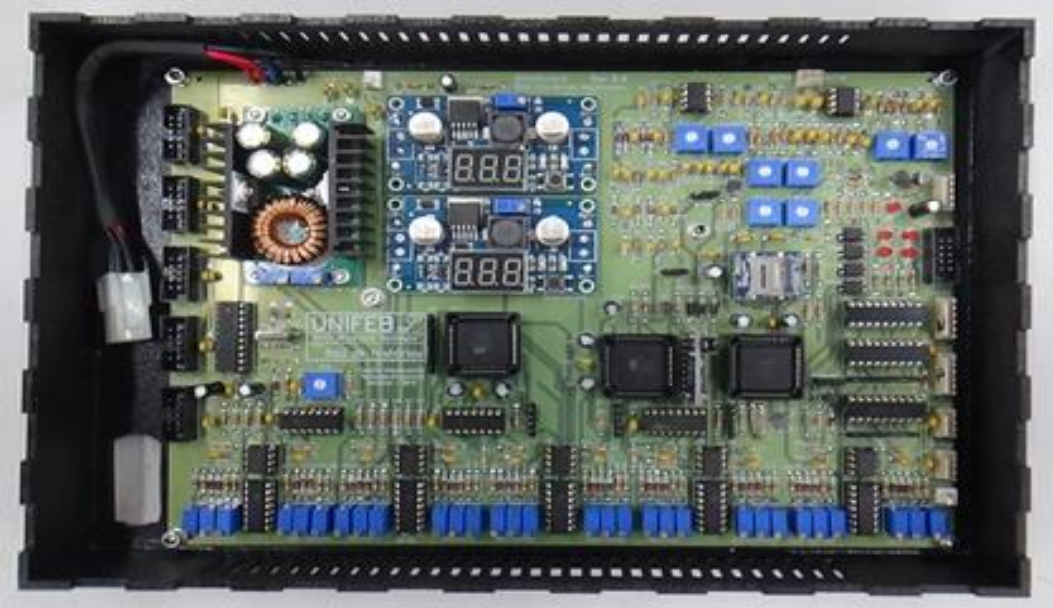

Fonte: Própria

Devido à alta complexidade do circuito eletrônico no que diz respeito à engenharia de controle e software aplicados nesta topologia, neste momento, será discutida apenas a metodologia aplicada aos comandos do robô, deixando para outro artigo os tópicos relacionados aos conceitos e descrição dos circuitos e firmware de controle. No entanto, um detalhe importante a ser mencionado foi a forma encontrada para simular de modo convincente os movimentos da boca e dos lábios durante a fala. Por meio de um comando que 
liga e desliga a reprodução da fala, quando ligado, os atuadores da boca e dos lábios passam a se movimentar simulando um Bargraph VU Meter (medidor de pico de áudio). O micro processador gera os sinais de PWM para os servos motores mencionados variando o período de trabalho em função da amplitude do sinal de áudio.

Os comandos de movimento do robô animatrônico são enviados ao micro processador de animação através de um sinal DTMF (Dual Tone Multi Frequency - Multi-frequência de Tom Duplo) (Application Note MSAN108 MITEL, 2004) gravado em sincronismo com o áudio da história a ser contada. Estes sinais assim como todo o áudio da história incluindo trilha sonora, voz e efeitos de sonoplastia são editados por meio da plataforma Windows e do aplicativo GoldWave. No canal direto, é gravado o áudio da história já roteirizado e no canal esquerdo são gravados os comandos em DTMF sincronizados com o roteiro da história, Figura 2.7.

Figura 2.7 - Espectro de Áudio com os comandos DTMF

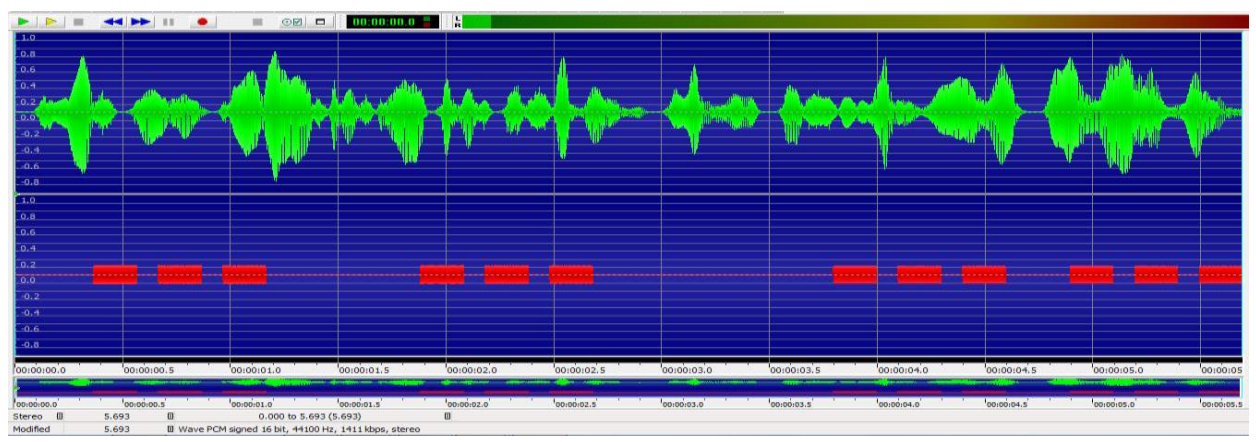

Fonte: Própria

O sistema DTMF desenvolvido inicialmente para aplicações em telefonia (MARTINS, 2002) usa um conjunto de oito frequências de áudio mescladas em pares para representar 16 sinais, representados pelos dígitos de zero a nove, pelas letras A a D e pelos símbolos \# e * do teclado de um telefone. Os comandos criados para a animação do robô utilizam sempre uma combinação de três duplos tons dentre as dezesseis possíveis do sistema DTMF para ordenar uma ação. Foi criada uma tabela de comandos com os sinais DTMF, previamente gravados em arquivos de áudio, que controlam os movimentos da face do robô e estes arquivos por meio de um roteiro são mixados ao áudio da história editada. Por exemplo, o comando DTMF "B01" liga a fala do robô e o comando "B02" desliga a fala. A abertura do baú, assim como todos os efeitos de luz, fumaça, elevação do busto para fora da caixa e demais movimentos possuem um comando específico.

Depois de o áudio ser editado, roteirizado e sincronizado com os comandos DTMF, ele é convertido para MP3 e guardado em um cartão micro SD. Este cartão é então inserido no hardware de controle do robô e o arquivo áudio é executado por meio de um acionamento que fica no botão da tranca do baú. O baú então se abre e a história passa a acontecer. No final da história, por um comando também gravado em sincronismo com o áudio, o robô animatrônico se recolhe por meio da plataforma de elevação e o baú se fecha sozinho.

\section{DISCUSSÃO}

O trabalho futuro para este projeto tende a ser muito extenso, houve uma engenharia aplicada muito complexa para ser absorvida em um tempo tão curto. O sistema mecânico dos 
atuadores se mostrou eficiente quanto à sua performance, mas para os movimentos da boca e dos lábios não houve um bom desempenho quanto à velocidade ou tempo de resposta. Fica também como sugestão para as próximas equipes, o desenvolvimento de aplicativo com interface gráfica animada que possa auxiliar a edição do áudio com o sincronismo dos comandos. Hoje, da forma que está, faz-se necessário mixar o áudio com o comando e em seguida executar o arquivo no hardware do robô para conferir se a animação é a esperada para o aquele momento do roteiro. Este modo de verificação da forma que está se mostrou eficaz quanto aos movimentos esperados para o roteiro de história, mas um tanto moroso para finalização do arquivo editado.

\section{CONCLUSÃO}

A interação entre os dois cursos cumpriu a função de trabalhar uma 'série de competências próprias do trabalho colaborativo atualmente necessário na formação de ambas as áreas profissionais, tal qual sugerido por Coda (2016). Esta interação desempenhou um papel importante ao incentivar os alunos a entender o básico da robótica, a atividade de projetar, modelar, montar e controlar um animatrônico, deixando de lado os temores de complexidade ou dificuldade associados ao tópico. A motivação também foi afetada, pois os alunos encontraram mais interesse em programar e controlar os mecanismos. Os objetivos iniciais foram alcançados, tanto em termos técnicos na construção do aparelho, como pedagógicos, quanto à aprendizagem interdisciplinar dos alunos envolvidos. A integração entre Pedagogia e Engenharia ocorreu por meio do Centro de Inovação Tecnológica (CIT) do UNIFEB, conforme proposta inicialmente elaborada para tal finalidade. Trabalhos futuros se concentrarão na expansão da experiência para outros grupos de alunos.

\section{REFERÊNCIAS}

BENDER, William, N. Aprendizagem baseada em projetos: educação diferenciada para o século XXI. Porto Alegre: Penso, 2014.

BERGMANN, Jonathan. SAMS, Aaron. Sala de aula invertida: Uma metodologia ativa de aprendizagem. Rio de Janeiro: LTC, 2016.

CADEMARTORI, Lígia. O que é literatura infantil. São Paulo: Brasiliense, 2008

CODA, Roberto. Competências Comportamentais: como mapear competências pessoais no trabalho. São Paulo: Atlas, 2016.

CRAIG, John. J. Robótica, São Paulo: Pearson Education do Brasil, 2013.

FAZENDA, Ivani. O que é interdisciplinaridade. São Paulo: Cortez, 2017.

GIMENEZ, Salvador Pinillus. Microcontroladores 8051 - Teoria e Prática, São Paulo:

Editora Érica, 2010.

HANSON ROBOTICS. (2009). We Bring Robots to Life. Retrieved from Hanson Robotics:

Disponível em: https://hansonrobotics.wordpress.com/ Acesso em: 19 abr. 2020.

HORN, Michael, B. ; STAKER, Haether. Blended: usando a inovação disruptiva. Porto

Alegre/RS: Penso Ed. Ltda / Grupo Educação S.A. 2014.

LAJOLO, Marisa. e ZILBERMAN, Regina. Literatura infantil Brasileira: Histórias e Histórias. São Paulo: Ed. Ática, 2010

LEAL, Edvaldo. Araújo. MIRANDA, Gilberto José, NOVA, Silvia Pereira de Castro, Casanova. Revolucionando a Sala de Aula: Como Envolver o Estudante Aplicando as Técnicas de Metodologias Ativas de Aprendizagem. S. Paulo: Atlas, 2017.

MARSIGLIA, Ana Carolina Galvão. A prática pedagógica histórico-crítica na educação infantil e ensino fundamental. Campinas, SP: Autores Associados, 2011. 
MARTINS, Roberto. A Fundamentação da Telefonia através da História - Parte 1: Da Invenção ao

Início do Século XX (pesquisa realizada para a Fundação Telefônica, em 2002).

MASETTO, Marcos Tarcísio. Competência Pedagógica do Professor Universitário. $2^{\mathrm{a}}$ edição, São Paulo: Summus, 2012.

MITEL SEMICONDUCTOR. Applications of the MT8870 integrated DTMF Receiver. Application Note MSAN-108 MITEL, 2004.

MORAN, José Manuel, MASETTO, Marcos Tarcísio, BEHRENS, Marilda. Aparecida. Novas Tecnologias e Mediação Pedagógica. 19ª edição, Campinas, SP: Papirus, 2012. OLIVEIRA, Vanderli .Fava. de, A Engenharia e as novas DCN's. $1^{\text {a }}$.ed. Rio de janeiro: LTC,2019.

RAJAN, Mannaraswamighala Sreeranga, SEYEZHAI, Ramalingam. Comparative study of multicarrier pwm techniques for a modular multilevel inverter. International Journal of Engineering and Technology (IJET), Citeseer, v. 5, n. 6, p. 4850-4865, 2013.

REIS, Fábio. (org.) Inovar para transformar. São Paulo: Cultura, 2018.

\title{
INTERSISCIPLINARY LEARNING: CONSTRUCTION OF AN ANIMATRONIC ROBOT ABLE TO TELL STORIES FOR CHILDREN
}

\begin{abstract}
The report of this article refers to an interdisciplinary experience in Electrical Engineering and Pedagogy courses. It refers to the construction of an animatronic robot with human features and the appearance of an old witch who rises from a wooden chest and interacts with the audience by telling children's stories created by students in the Pedagogy course. The project was developed by teachers and students of the courses mentioned above and coordinated by the Center for Technological Innovation (CIT) of UNIFEB. The good technical and professional interaction between all involved was essential for the success of the initial proposal.
\end{abstract}

Keywords: Animatronic robots, Interdisciplinary teaching, Electrical engineering, Children's storytelling. 